\title{
Evaluasi Kinerja Si Pendataan Umat Menggunakan Framework Cobit 5 (MEA 01) Gereja ST. Paulus Miki Salatiga
}

\author{
Shera Marsela' ${ }^{1}$, Agustinus Fritz Wijaya ${ }^{2}$ \\ 1,2Sistem Informasi, Fakultas Teknologi Informasi, Universitas Kristen \\ Satya Wacana
}

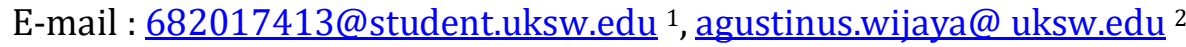

\begin{abstract}
Abstrak
Dalam sebuah perusahaan tidak hanya fokus pada penerapan teknologi informasi (TI), tetapi juga pada penerapan monitoring, evaluasi dan penilaian kerja, serta kesesuaian TI. Oleh karena itu, peneliti menggunakan domain Monitor, Evaluate, Asess (MEA). Tujuan dari penelitian ini yaitu untuk mengetahui tingkat kapabilitas atau kematangan teknologi informasi pada gereja St. Paulus miki salatiga. Metode penelitian yang digunakan adalah kualitatif. Hasil dari penelitian ini adalah untuk mengetahui tingkat kapabilitas serta memberikan rekomendasi atau masukkan kepada gereja st. Paulus miki agar lebih baik untuk kedepannya.
\end{abstract}

\section{PENDAHULUAN}

Perkembangan teknologi yang semakin cepat telah membawa dunia memasuki era baru khususnya dibidang informasi dan bahkan lebih cepat dari yang pernah dibayangkan sebelumnya. Sistem Informasi merupakan aset bagi suatu perusahaan yang bila diterapkan dengan baik akan memberikan kelebihan untuk berkompetensi sekaligus meningkatkan kemungkinan bagi kesuksesan suatu usaha. [1]. Peranan sistem informasi pada setiap perusahaan berbeda-beda. Ada yang menggunakan sistem informasi hanya sebagai alat bantu untuk pencapaian tujuan organisasi, adapula perusahaan yang menggunakan sistem informasi sebagai sesuatu 
https://journal-computing.org/index.php/journal-cisa/index

yang berfungsi secara strategis. Untuk mengetahui apakah kinerja sistem informasi sesuai dengan perencanaan dan tujuan usaha yang dimilikinya maka harus dilakukan pengukuran. Hasil dari pengukuran digunakan oleh manajemen untuk melakukan perbaikan terhadap kinerja SI. Evaluasi SI merupakan wujud dari pengukuran itu. [2]

Pendataan Umat merupakan salah satu komponen dasar terpenting dari Gereja, karena merupakan lembaga keagamaan dengan jumlah pengikut yang besar. Pendataan umat yang teratur akan menghasilkan informasi yang efektif, sehingga para petugas di lapangan terbantu dalam mengembangkan pelayanan bagi jemaat. [3] Sebelumnya GPM (Gereja Paulus Miki) belum memiliki model pendataan umat yang teratur. Seluruh data umat masih diproses secara manual atau masih desktop. Akibatnya, Gereja tidak bisa memberikan informasi dengan cepat ketika pastor dan umat membutuhkannya. Selain itu, data yang ada tidak dapat dianalisa dan diproses lebih lanjut untuk tujuan yang lebih besar dan lebih penting. Oleh karena itu, gereja sangat membutuhkan aplikasi pendataan umat yang dapat memberikan informasi dengan cepat. Data umat ini nantinya akan diolah dan dijadikan bahan pertimbangan untuk memprediksi pelayanan kepada umat. Pendataan umat yang berbasis data tersebar merupakan solusi yang dapat membantu memenuhi kebutuhan Keuskupan Purwokerto yang memiliki 22 paroki. Masing-masing paroki juga memiliki umat yang cukup beragam. Pada Januari 2020, keuskupan memberikan pelatihan penerapan sistem pendataan umat berbasis wab. Kemudian sekitar Maret 2020, baru diimplementasikan oleh semua paroki termasuk Gereja Paulus Miki Salatiga (GPM). Pengelompokan paroki yang datanya diinput ke dalam beberapa server akan memudahkan sistem untuk dapat mengatur dan menganalisis data secara cepat sesuai dengan kebutuhan yang ada. Mekanisme sistem ini hanya dapat dijalankan kalau sistem yang dibangun berbasis data tersebar. Sistem ini berisi data kependudukan yang telah terintregasi dengan dicapil yang terkait dengan nomor NIK (Nomor Induk Kependudukan) dan nomor KK (Kartu Keluarga), serta data sacramental (Babtis, Krisma, Perkawinan). Untuk data sacramental yang menginput adalah dari gereja atau sekretariat sedangkan data 
kependudukan yang menginput adalah dari lingkungan. Sistem pendataan umat berbasis wab ini dapat memberikan informasi yang akurat kepada umat yang membutuhkan, dan memproses data untuk kebutuhan yang lebih penting dan lebih luas. Itu juga bisa diakses langsung dari keuskupan.

Framework Cobit 5 Framework COBIT (Control Objectives For Information and Related Technology) 5 merupakan generasi terbaru dari panduan ISACA yang dibuat berdasarkan pengalaman penggunaan COBIT selama lebih dari 15 tahun oleh banyak perusahaan dan penggunaan dari bidang bisnis, komunitas, teknologi informasi, risiko, asuransi, dan keamanan. Framework COBIT 5 mendefinisikan dan menjelaskan secara rinci sejumlah tata Kelola dan manajemen proses, Framework COBIT 5 juga menyediakan kerangka kerja yang komprehensif sehingga membantu perusahaan dalam mencapai tujuan mereka dalam tata kelola dan manajemen aset informasi perusahaan dan teknologi. Secara sederhana, membantu perusahaan menciptakan nilai yang optimal dari TI dengan menjaga keseimbangan antara mewujudkan manfaat dan mengoptimalkan tingkat resiko dan penggunaan sumber daya. Framework COBIT 5 menggunakan praktik tata kelola dan manajemen untuk menjelaskan tindakan praktik yang baik untuk efek tata kelola dan manajemen teknologi informasi perusahaan. Framework COBIT 5 terdiri dari 5 domain, yaitu EDM, APO, BAI, DSS, dan MEA. [4] Rumusan masalah yang didapat dari penelitian ini yaitu, Bagaimana tingkat kapabilitas dan bagaimana strategi perbaikan yang harus dilakukan dalam pendataan umat di Gereja Paulus Miki Salatiga. Sedangkan tujuan dari penelitian ini yaitu untuk mengetahui seberapa besar level tingkat kapabilitas dan memberikan strategi perbaikan dalam implementasi pendataan umat dengan menggunakan framework COBIT 5 domain Monitor, Evaluate, dan Assess (MEA) di Gereja Paulus Miki Salatiga.

Penelitian terdahulu yang dapat mendukung penelitian ini yaitu; Pertama, penelitian yang berjudul “ Analisis Tingkat Kapabilitas Sistem Informasi Rumah Sakit Berdasarkan COBIT 5 (MEA 01) Pada RSUD Tugurejo Semarang". Tujuan dari penelitian tersebut yaitu untuk mengetahui tingkat kapabilitas dan strategi perbaikan untuk proses pengawasan, evaluasi dan penilaian kerja serta kesesuaian TI. Metode pengumpulan 
https://journal-computing.org/index.php/journal-cisa/index

data penelitian ini menggunakan studi dokumen, kuisioner dan wawancara kemudian dianalisis tingkat kapabilitas dan kesenjangan. Tingkat kapabilitas yang didapat dari hasil penelitian yaitu berada level 2 (Managed). Hal ini menunjukkan bahwa proses pengawasan, evaluasi dan penilaian kinerja, dan kesesuaian TI berada pada tahap dikelola. [5]. Kedua, penelitian yang berjudul "Evaluasi Sistem E-Goverment Berdasarkan Cobit 5 Dengan Domain MEA01 Pada Badan Kepegawaian Daerah Kota Semarang". Tujuan dari penelitian tersebut yaitu melakukan audit tata kelola sistem E-Government kepegawaian di Badan Kepegawaian Daerah Kota Semarang dengan acuan dari kerangka kerja COBIT versi 5. Domain yang di gunakan dalam COBIT 5 ini adalah Monitoring, Evaluate, and Assess (MEA). Metode pengumpulan data penelitian ini menggunakan studi observasi, wawancara, dokumentasi, dan kuisioner kemudian dianalisis tingkat kapabilitas dan kesenjangan. Berdasarkan hasil kuisioner maka kriteria tersebut memenuhi kriteria pada level 2 (Managed) yaitu pada PA 1.1 berstatus Fully Achieved, PA 2.1 berstatus Largely Achieved, dan PA 2.2 berstatus Largely Achieved. [6]. Ketiga, penelitian yang berjudul “ Evaluasi Kinerja Sistem Informasi Kepegawaian pada Dinas Kependudukan dan Catatan Sipil Salatiga Menggunakan COBIT 5". Tujuan dari penelitian untuk mengukur tingkat kematangan teknologi informasi pada dinas kependudukan dan catatan sipil kota salatiga. Metodologi penelitian ini adalah metode kualitatif, dengan mengumpulkan data dan wawancara dengan informan. Berdasarkan penilaian sistem infromasi absensi disdukcapil masih berada pada level 1 ( Performed Process ). [7]

Pendataan Umat adalah salah satu komponen dasar yang sangat vital di dalam Gereja, sebagai salah satu lembaga agama yang memiliki jumlah umat yang cukup banyak. Pendataan Umat yang teratur akan menghasilkan informasi yang cepat dan akurat, sehingga para petugas di lapangan terbantu dalam mengembangkan pelayanan bagi jemaat. Evaluasi kinerja sistem adalah metode untuk mengevaluasi apakah sistem yang sedang berjalan sudah sesuai dengan yang dibutuhkan dalam suatu organisasi. [8] 
COBIT 5.0 memiliki 5 domain yang terbagi dalam domain governance dan management, masing- masing domain memiliki proses untuk mencapai tujuannya, yaitu domain Evaluate, Direct, and Monitor (EDM) terdapat 5 proses, Align, Plan and Organize (APO) terdapat 13 proses, Build, Acquire and Implement (BAI) terdapat 10 proses, Deliver, Service and Support (DSS) terdapat 6 proses, Monitor, Evaluate and Assess (MEA) terdapat 3 proses. COBIT 5.0 yang berfokus pada MEA terdiri dari enam Control Objective, yaitu : [9]

1. MEA01 Pengawasan, Evaluasi dan Penilaian Kinerja, dan Kesesuaian (Monitor, Evaluate and Assess Performance, And Comformance)

2. MEA02 Pengawasan, Evaluasi, dan Penilaian Sistem dari Kontrol Internal (Monitor, Evaluate, and Assess The Systems of Internal Control)

3. MEA03 Pengawasan, Evaluasi, dan Penilaian Sistem Kebutuhan Eksternal (Monitor, Evaluate and Assess Compliance with External Requirements)

\section{Process Capability Model (PCM)}

Process Capability Model digunakan untuk mengukur tingkat kematangan IT enterprise, diadopsi dari ISO/IEC 15504 sebagai standar proses penilaian. Process Capability Model menyediakan pengukuran performasi pada proses-proses pada area governance dan management. [10] Terdapat enam tingkat kapabilitas model. Tingkat kapabilitas suatu proses diukur berdasarkan penilaian terhadap process attributes (PA) pada setiap level. Setiap atribut mendefinsikan aspek tertentu dari kapabilitas proses. PA digunakan untuk menilai apakah proses telah mencapai tujuan atau belum. Namun tidak berlaku pada level 0 yaitu incomplete karena pada level ini tidak dijalankan atau gagal dalam mencapai tujuan proses sehingga tidak memiliki atribut. Berikut tingkat dari Process Capability Model beserta PA pada setiap proses [9].

a. Level 0 - Proses Tidak Lengkap (Incomplete Process) Proses tidak diimplementasikan atau gagal untuk mencapai tujuan 
https://journal-computing.org/index.php/journal-cisa/index

prosesnya. Pada level ini tidak ada bukti dari setiap pencapaian sistematis tujuan proses.

b. Level 1 - Proses Dilakukan (Performed Process) Proses diimplementasikan mencapai tujuan prosesnya.

c. Level 2 - Proses dikelola (Managed Process) Proses yang dilakukan sekarang diimplementasikan dengan cara dikelola (direncanakan, dimonitor, dan disesuaikan) dan produk kerjanya secara tepat ditetapan, dikontrol, dan dipelihara.

d. Level 3 - Proses Ditetapkan (Established Process) Proses yang dikelola sekarang diimplementasikan menggunakan proses definisi yang mana mampu mencapai hasil prosesnya.

e. Level 4 - Proses Dapat Diramalkan (Predictable Process) Proses yang didirikan sekarang beroperasi dalam batas-batas yang didefinisikan untuk mencapai hasil prosesnya.

f. Level 5 - Proses Dioptimalkan (Optimising Process) Proses diprediksi yang terus ditingkatkan untuk memenuhi arus yang relevan dan tujuan bisnis proyek.

\section{METODE PENELITIAN}

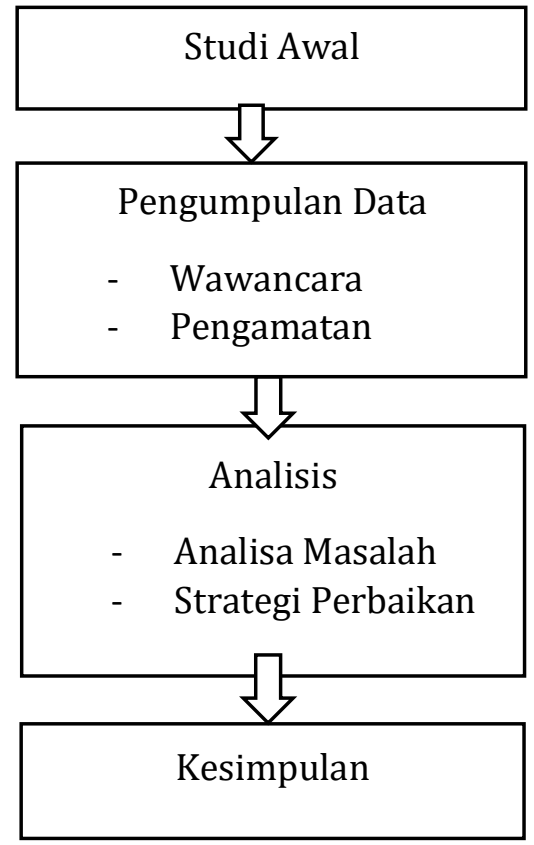

Shera Marsela, Agustinus Fritz Wijaya | 73 
Metode yang digunakan dalam penelitian ini adalah menggunakan metode deskriptif kualitatif dimana hasil pengumpulan data dideskripsikan berdasarkan perspektif narasumber dengan melakukan wawancara. Berbagai tahapan dalam penelitian ini terbagi menjadi beberapa aktivitas sebagai berikut: Untuk tahap pertama yaitu mempelajari tentang obyek studi awal dengan mengamati dan melihat sistem pendataan umat yang digunakan oleh Gereja Paulus Miki Salatiga. Tahap kedua yaitu mengumpulkan data dengan melakukan wawancara langsung dari narasumber untuk memperoleh temuan mengenai penerapan pendataan umat, serta pengamatan dengan memantau langsung keadaan sistem dan melihat data keluaran yang ada. Tahapan ketiga yaitu menganalisa tingkat kematangan atau kapabilitas, kemudian memberikan rekomendasi atau strategi perbaikan untuk pengembangan dimasa mendatang. Tahapan terakhir yaitu menarik kesimpulan berdasarkan hasil analisis data dan rekomendasi atau strategi perbaikan dimasa mendatang terkait pendataan umat di Gereja Paulus Miki Salatiga.

\section{HASIL DAN ANALISA}

Berdasarkan hasil pengumpulan data dan wawancara yang dilakukan terhadap sistem pendataan umat di Gereja Paulus Miki Salatiga, bahwa Gereja Paulus Miki terkait dengan pendataan umat masih diproses secara manual atau masih Desktop dan baru mulai mengimplementasikan sistem pendataan umat yang telah dikembangkan oleh keuskupan pada Maret 2020. Sebelumnya pada Januari 2020 Gereja Paulus Miki Salatiga sudah mendapatkan pelatihan oleh keuskupaan dalam menggunakan sistem pendataan umat berbasis wab. Untuk bagian sistemnya sendiri sudah terakomodasi untuk digunakan oleh semua paroki namun masih terdapat kendala dalam mendata setiap umat dilingkungan masing-masing. Terutama terkait Sumber Daya Manusia nya yang masih mengalami kesulitan atau belum proaktif dalam mengoperasikan sistem pendataan umat ini dikarenakan faktor usia dan belum ada pelatihan disetiap lingkungannya. Sehingga masih ada data umat yang belum semua terinput kesistem, dan masih ada data yang tidak terupdate. Oleh karena itu dari gereja atau bagian secretariat membutuhkan bantuan, Maka dibentuklah 
https://journal-computing.org/index.php/journal-cisa/index

tim pendataan umat, yang bertugas untuk menginput awal data-data yg belum semua terinput. Namun apabila ada perubahan atau update data semisal ada umat yang meninggal atau pindah maka itu akan diupdate oleh ketua lingkungannya masing-masing. Pendataan Umat ini tidak hanya dioptimalkan untuk data kependudukan saja namun juga untuk kebutuhan sakramen, bantuan sosial, dan bantuan pendidikan. Untuk data sacramental yang menginput yaitu dari gereja atau sekretariat seperti Babtis, Krisma, Perkawinan, sedangkan data kependudukan yang menginput yaitu dari lingkungan atau oleh tim pendatan umat. Umat juga bisa mengupdate datanya sendiri tetapi hanya pada biodata terkait dengan data kependudukan, seperti pada tanggal lahir, alamat, nama anak atau istri dan lain sebagainya. Untuk bantuan sosial dan bantuan Pendidikan yang bertugas yaitu tim pendataan umat, disana mereka akan melakukan suvei kesetiap lingkungan untuk melihat langsung kondisi rumah setiap umat. Berdasarkan hasil observasi terhadap tingkat kematangan atau kapabilitas kinerja SI Pendataan Umat Gereja Paulus Miki, maka diperoleh hasil tingkat kematangan untuk domain MEA ( Monitor, Evaluate, and Assess ) berada pada level 1 atau Perfomed Process yang berarti bahwa Gereja Paulus Miki telah melaksanakan proses SI yang telah di implementasikan dengan baik. Adapun target atau strategi perbaikan untuk perbaikan dimasa yang akan datang dari kondisi saat ini (level 1) terkait dengan kondisi yang akan dicapai yaitu pada level 2 atau Managed Process. Supaya mencapai kondisi yang dicapai maka perlu adanya pelatihan kepada umat di lingkungan masing-masing, dan sosialisasi terhadap umat, serta maintenance pada sistem pendataan umat apabila ada saran atau masukkan yang nantinya bisa diusulkan kepada keuskupan. Harapannya dalam waktu 2 tahun kedepan semua lingkungan sudah bisa mendata umatnya dengan baik sehingga bisa tercapai tingkat kapabilitas yaitu pada level 2. Seperti yang telah terpapar pada spider chart diagram berikut ini. 
https://journal-computing.org/index.php/journal-cisa/index

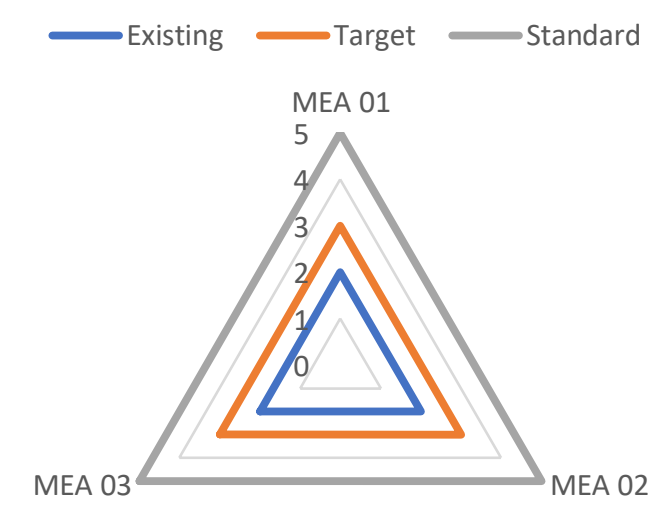

\section{KESIMPULAN}

Berdasarkan hasil pembahasan yang diperoleh dari penelitian ini, maka dapat disimpulkan bahwa proses yang terdapat pada domain MEA (Monitor, Evaluate, and Assess) pada COBIT 5 ini baru mencapai pada level 1 atau Performed Process dikarenakan sistem pendataan umat ini baru diterapkan dan belum bisa dilkelola secara mandiri atau belum mencapai ke level 2 (Manage Prosess). Harapan kedepannya bisa mencapai pada tingkat kapabilitas level 2 agar penerepan teknologi informasi masa yang datang bisa lebih baik lagi

\section{DAFTAR PUSTAKA}

[1] S. Dewi, L. M. Jannah, and Y. Jumaryadi, “Analisis Dan Perancangan Sistem Informasi Manajemen Aset Tetap Pada Pt. Metis Teknologi Corporindo," J. Sist. Informasi, Teknol. Inf. dan Komput., 2018.

[2] Tri Oktarina, "Tata Kelola Teknologi Informasi Dengan Cobit 5," Tata Kelola Teknol. Inf. Dengan Cobit 5, 2017.

[3] L. D. T. Utami, "Pembangunan Sistem Informasi Umat Gereja 


\section{Journal of Computer and Information Systems Ampera}

Vol. 2, No. 2, May 2021 e-ISSN: 2775-2496

https://journal-computing.org/index.php/journal-cisa/index

Berbasis Web," 2014.

[4] ISACA, COBIT 5 Framework. 2012.

[5] A. Nugroho \& Fahmi, "Analisis Tingkat Kapabilitas Sistem Informasi Rumah Sakit Berdasarkan Cobit 5 ( Mea01 ) Pada Rsud," Techno.COM, 2015.

[6] V. Zhafarina and S. Wibowo, "Evaluasi Sistem E-Goverment Berdasarkan Cobit 5 Dengan Domain MEA01 Pada Badan Kepegawaian Daerah Kota Semarang," JOINS Uournal Inf. Syst., 2016.

[7] Z. M. Naskay and A. F. Wijaya, "Evaluasi Kinerja Sistem Informasi Kepegawaian pada Dinas Kependudukan dan Catatan Sipil Salatiga Menggunakan COBIT 5," J. Bina Komput., 2020, doi: 10.33557/binakomputer.v2i1.807.

[8] Noorhasanah, W. W. Winarno, and D. Adhipta, "Evaluasi Tata Kelola Teknologi Informasi Berbasis Framework COBIT 5," Eval. TATA KELOLA Teknol. Inf. Berbas. Framew. COBIT 5 Semin. Nas. Teknol. Inf. dan Multimed. 2015, 2015.

[9] COBIT 5, “COBIT 5: Process Assessment Model (PAM)," ISACA, 2013.

[10] J. Fernandes Andry, "Process Capability Model Based on COBIT 5 Assessments (Case Study)," Jl. Lodan Raya, 2016. 